\title{
AS MARCAS DA AVALIAÇÃO NO PROCESSO DE ESCOLARIZAÇÃO DE UM ALUNO COM DEFICIÊNCIA INTELECTUAL
}

Amélia Maria Mesquita Renata Andrade Sobras ${ }^{(*)}$

\section{INTRODUÇÃO}

O texto ora apresentado é um recorte da pesquisa de mestrado que objetivou discutir a trajetória de escolarização na educação básica de um aluno com deficiência intelectual. Neste texto, colocamos em evidência um aspecto muito forte na narrativa do sujeito: o processo de avaliação. Assim, objetivamos neste artigo problematizar os processos avaliativos vividos por um aluno com deficiência intelectual (DI) durante a educação básica.

Vale destacar que buscar na avaliação elementos para compreender a trajetória de escolarização de um aluno com deficiência intelectual ao longo da educação básica coloca-se como uma possibilidade para pensarmos a escola e seus mecanismos de inclusão/exclusão.

Cabe destacar que concordamos com Carvalho (2005, p. 15) ao afirmar que:

A inclusão escolar deve ser entendida como princípio (um valor) e como processo contínuo e permanente. Não deve ser concebida como um preceito administrativo, dado "a priori", que leva a estabelecer datas, a partir das quais as escolas passam a ter o estado de inclusivas, em obediência à hierarquia do poder ou a pressões ideológicas.

Sob tal enfoque, a produção deste texto se deu a partir da necessidade de colocar em evidência como ocorreu o processo de avaliação durante a trajetória de escolarização de um indivíduo com deficiência intelectual.

Assim, nos motivamos a pesquisar o seguinte problema: Como se constituiu o processo avaliativo de um aluno com deficiência intelectual em diferentes paradigmas educativos durante sua trajetória de escolarização na educação básica?

\footnotetext{
${ }^{(*)}$ Universidade Federal do Pará
} 
Para tanto, fizemos o recorte da categoria avaliação, como um dos elementos fortemente presentes na fala e documentação do aluno, que viveu uma história de escolarização de 26 anos, distribuídos entre a escola regular, a classe especial, a instituição especializada e a escola regular novamente, iniciada em 1985 e concluída em 2011.

Os dados foram coletados por meio da entrevista semiestruturada aplicada três vezes junto ao sujeito da pesquisa. A primeira entrevista foi realizada apenas com o uso de um roteiro. Contudo, ao perceber a dificuldade de uma organização temporal da memória referente à trajetória, foi necessário usar suportes como alguns cadernos e relatórios que ajudaram na realização dos dois outros encontros de forma a conseguir depreender o maior número possível de informações sobre sua trajetória, conseguindo perceber as nuance de cada momento do aluno (aqui denominado JC) na escola.

Assim, no cotejamento das falas do sujeito, com os seus registros de avaliação nas diferentes escolas onde transitou e o referencial teórico, identificamos pistas que tanto revelam a relação da escola com o aluno com deficiência, bem como a relação deste com a escola, relações essas que nos ajudam a problematizar o processo de avaliação vivido por JC.

\section{ESCOLARIZAÇÃO E AVALIAÇÃO: QUE PERSPECTIVAS PARA O PARADIGMA INTEGRATIVO E INCLUSIVO?}

Educação e escolarização nem sempre estiveram atrelados ao espaço formal da escola, pois, o significado atribuído à educação é bem mais amplo que o próprio conceito de escola. Mesmo antes dos sistemas escolares, as gerações já se educavam. No entanto, com o passar do tempo e à medida que as sociedades vão se modificando, a educação passa a ser formalizada por meio da escolarização.

Então achamos necessário esclarecer o que é escolarização. Segundo Baptista, escolarização é:

[...] O complexo processo que envolve aspectos relacionados com a instituição escolar: a quem é oferecida, qual a sua função, sua organização, seu currículo, a tecnologia a sua disposição (livros, recursos e materiais utilizados para a escrita, entre outros), a forma e o princípio das ações pedagógicas desenvolvidas em seu interior, o sistema escolar (se é constituído ou não), entre outros, inclui os saberes culturais associados a determinados grupos profissionais e a transformação destes em disciplinas escolares. (2015, p. 53) 
Se o conceito de escolarização está relacionado a quem se destina a instituição escolar, percebemos que a educação começa a projetar as relações de poder, que irão determinar quem tem acesso a ela.

Outra perspectiva em relação ao conceito de escolarização é a de Faria Filho, que percebe escolarização por meio de um duplo sentido. Para o autor, em um primeiro sentido escolarização é:

O estabelecimento de processos e políticas concernentes à "organização" de uma rede, ou redes, de instituições, mais ou menos formais, responsáveis seja pelo ensino elementar da leitura, da escrita, do cálculo e, no mais das vezes, da moral e da religião, seja pelo atendimento em níveis posteriores e mais aprofundados. (FARIA FILHO, 2002, p. 111).

Em um segundo sentido, entende escolarização como "o processo e a paulatina produção de referências sociais tendo a escola, ou a forma escolar de socialização e transmissão de conhecimentos, como eixo articulador de seus sentidos e significados" (FARIA FILHO, 2002, p. 111). Ambos os sentidos estabelecidos pelo autor compreendem a escolarização como uma instituição organizada, com conhecimentos definidos e práticas escolares estabelecidas, uma escola configurada para dar conta de atender determinados sujeitos. É a partir dessa perspectiva que discutiremos a escolarização e a avaliação como um elemento constitutivo desta, no paradigma integrativo e inclusivo.

\subsection{ESCOLARIZAÇÃO NA ESCOLA ESPECIAL: QUE ENFOQUE DE AVALIAÇÃO?}

Falar sobre avaliação de alunos com deficiência no período anterior ao paradigma inclusivo remete às concepções sobre o desenvolvimento das pessoas com deficiência intelectual ainda fortemente baseadas nos diagnósticos médicos, consequentemente aos testes de inteligência, os conhecidos testes de QI (Quociente de Inteligência). O QI, de acordo com Mazzota (1987), é um índice utilizado para calcular a inteligência, estabelecendo uma relação entre a idade mental da pessoa e sua idade cronológica, introduzido por Alfred Binet, seus testes foram rapidamente difundidos entre os estudiosos do campo da psicologia.

Esses testes eram amplamente utilizados pela psicologia como forma de continuar organizando classes homogêneas, com o pretexto de "favorecer" o processo de ensino aprendizagem. O movimento que foi sendo desenhado era o de que, baseado nos testes de desempenho e inteligência, alguns alunos na condição de pessoa com deficiência, poderiam transitar para o ensino regular. Como afirma Ferreira: 
No movimento de integração escolar, os serviços deveriam ser organizados de modo a permitir que os alunos com deficiência pudessem transitar de ambientes educacionais mais segregados, como a escola e a classe especial, para a classe comum do ensino regular, na qual receberia o suporte por meio, por exemplo, do ensino itinerante e das salas de recursos (FERREIRA, 2006, p.19)

Mesmo com esta nova perspectiva de escolarizar — onde o movimento que foi sendo construído era o de que, baseado na "capacidade" desse aluno, poderia transitar para a sala regular — as condições para a transição, estavam baseadas no grau de "severidade" e "rendimento" como argumento para que este progresso fosse plausível. Como afirmam Marchesi e Martin (1995), a transição de um nível para outro deveria ocorrer, quando o aluno apresentasse condições quanto ao seu nível de aprendizagem.

Durante o decorrer do século XX, esses testes "avaliativos" não foram bem vistos. Segundo Pletsch (2010), a concepção de deficiência explicitada pela AMRR sofreu fortes críticas por pesquisadores brasileiros devido ao fato de "enfatizar demasiadamente o sujeito e suas limitações com base em resultados psicométricos, sem levar em consideração o contexto social" (PLETSCH, 2010, p. 106).

Contudo, os testes de QI, permaneceram "sentenciando" os alunos com deficiência que permaneceriam nas classes especiais ou escolas especializadas e aqueles que deveriam ir ao ensino regular. No âmbito das instituições especializadas para alunos com deficiência intelectual, como exemplo da Sociedade Pestalozzi, os alunos eram avaliados em sua maioria por atividades voltadas para o "treino". Como afirma Cruz (1988, p. 155) "Existe um processo educativo com uma homogeneização de grupos de alunos Portadores de Deficiência Mental, mais especificamente em nível treinável. [...] Atingindo as três fases do programa: a inicial, a medial e a terminal”.

Segundo Cruz (1988), a Instituição Pestalozzi funcionava introduzindo os Níveis I, II, III, que eram subdivididos em: socialização, parte motora e linguagem. Ainda de acordo com Cruz (1988, p. 159), a instituição denominava de "funções intelectuais", onde se constituíam os conteúdos mais “complexos" da instituição, nos quais o aluno passava por 3 níveis ${ }^{1}$, esses níveis aumentavam gradativamente o grau de dificuldade no processo de ensino aprendizagem. Segundo Cruz (1988), no nível 1 as atividades eram: a) desenvolver a memória visual, auditiva e sinestésica, através de jogos de memória e materiais variados; b) jogos de encaixe; c) fazer exercícios de movimentos sobre linhas traçadas em sala de aula e no recreio; d) localizar partes de seu corpo; e)

${ }^{1}$ O nível 2 das funções intelectuais, não consta em Cruz (1988). 
orientação espaço temporal. Já no nível 2 e 3 eram mais "complexas": a) discriminação de cores: verde, amarelo, azul e branco, através da separação de objetos da sala, sucata, jogos etc.; b) agrupamento de objetos da mesma categoria, cor, forma, tamanho e espessura; c) orientação espaço-temporal; d) discriminação do dia da semana, mês e ano; e) identificação de posições: aqui, ali, longe, perto, aplicando em várias situações; f) identificando tamanhos: utilizando objetos da sala; g) reconhecimento de sons variados;

Nota-se que Cruz (1988) não detalha como ocorriam os procedimentos avaliativos para que o aluno com deficiência mudasse de uma fase para outra. Na instituição Pestalozzi, levando a conclusão de que a escolaridade se apresentava com um viés voltado para a aprendizagem de atividades básicas do cotidiano, em ambos os níveis, as atividades têm como principal objetivo a autonomia desses alunos, sem a preocupação tão patente de problematizar os conteúdos abordados, conforme apontado nas pesquisas de Amaral (2004) e de Bueno, Mendes e Santos (2008).

Essa imprecisão quanto os processos avaliativos, é justificável, já que as escolas especiais funcionaram na maior parte do século passado, sem documentos legais que esclarecessem como deveria ser compreendida a avaliação naquele contexto de integração. Esta imprecisão resulta na forma como se compreendia a avaliação e como esta era realizada pelos docentes, sem a devida importância quanto à análise das possibilidades e avanços desses indivíduos. No entanto, era compreendida como um ato que exercia o "nivelamento" da inteligência; mesmo que o público que frequentasse esta escola possuísse a mesma deficiência, era necessário respeitar o potencial de cada um, além dos diferentes tempos e ritmos de aprendizagem.

O debate e as críticas em relação a este modelo de escolarização nos trouxeram ao nosso processo educativo contemporâneo nas salas regulares, que se estrutura basicamente da seguinte forma: a transmissão de conhecimento por um professor, normalmente através da linguagem oral durante as aulas, associados ao estudo dos livros e avaliações ao final do processo; o que exige dos alunos a compreensão do conteúdo, utilizando em grande parte deste processo a memória e a relação entre conceitos, o que lhe causa desvantagens durante a escolarização.

Ferreira (1992) também afirma que as práticas da escola especial perpetuavam um trabalho pedagógico pautado numa percepção abstrata do aluno e, portanto, descontextualizada. Isso ocasionou o desenvolvimento de ações e atividades massificadoras, generalizadas e repetitivas. Ideia fortalecida quando se observa que os conteúdos trabalhados e as avaliações nessas escolas, normalmente consideravam uma rotina de repetições que enfatizam a homogeneização dos alunos com deficiência intelectual a um "nível treinável". 
Dado o exposto, fica claro o contrassenso entre a organização do sistema educacional vigente e os princípios que regem a inclusão escolar.

\subsection{ESCOLARIZAÇÃO E AVALIAÇÃO NA ESCOLA REGULAR}

A escola, com sua possível provisoriedade, alicerçou-se em processos de escolarização que se estabeleceram por meios não democráticos, excludentes e segregadores de grupos menos privilegiados, incluindo aí os alunos com deficiência. Conforme Bueno, Mendes e Santos (2008, p. 270) "A maneira como a nossa sociedade reagiu e caracterizou as pessoas deficientes ao longo da história possibilita discutir as formas de escolarização atuais para esses alunos e todo o dilema da educação inclusiva que transcende os muros escolares".

No entanto, esse cenário sofre alterações através de mobilizações sociais e do fenômeno da urbanização, ligadas às transformações ocorridas mundialmente. Inicia-se um processo de ampliação da participação, tornando-se um fator essencial para o desenvolvimento social, na perspectiva de constituir sujeitos para o prosseguimento de estudos, pelo menos a nível legal. Como afirmam Bueno, Mendes e Santos (2008, p. 28):

[...] os processos de ampliação de oportunidades de acesso à escola pública, redundou, na atualidade, na quase universalização absoluta de acesso a esse nível de ensino, foram acompanhados por um forte comprometimento da sua qualidade, especialmente em razão de políticas públicas que pouco privilegiam esse aspecto.

Nesse processo de ampliação de oportunidades, o paradigma inclusivo se favorece, principalmente a partir da década de 1990 no Brasil, ganhando possibilidades reais de se efetivar, pelo menos enquanto prescrição.

O encontro entre inclusão e escolarização no ensino regular representa uma inovação para um país que, por séculos, negou, de modo elitista e seletivo, aos excluídos o direito ao conhecimento da escola sistemática e regular. ${ }^{2}$

A consequência disso reflete na dificuldade de uma escolarização plausível para esse coletivo de alunos. Esse conjunto de obstáculos encontrados na escola regular os processos avaliativos se configuram como coadjuvantes, fato este que se justifica pela inexistência de documentos legais que esclarecem ao docente como deveria ser compreendida a avaliação no

\footnotetext{
${ }^{2}$ Vale ressaltar que a política de inclusão apresenta finalidades e se constituiu como parte da política neoliberal.
} 
âmbito da educação inclusiva. Apenas em 2008 surge na "Política Nacional de Educação Especial na Perspectiva da Educação Inclusiva” um direcionamento a respeito, através do seguinte trecho:

A avaliação pedagógica como processo dinâmico considera tanto o conhecimento prévio e o nível atual de desenvolvimento do aluno quanto às possibilidades de aprendizagem futura, configurando uma ação pedagógica processual e formativa que analisa o desempenho do aluno em relação ao seu progresso individual, prevalecendo na avaliação os aspectos qualitativos que indiquem as intervenções pedagógicas do professor. No processo de avaliação, o professor deve criar estratégias considerando que alguns alunos podem demandar ampliação do tempo para a realização dos trabalhos e o uso da língua de sinais, de textos em Braille, de informática ou de tecnologia assistiva como uma prática cotidiana (BRASIL, 2008, p. 11).

Esse trecho da política remete como deve ser compreendida a avaliação, além de direcionar o docente sobre como proceder nesse processo, evidenciando que o ato de avaliar se constitui uma das principais funções da prática pedagógica do professor. Desta forma, é essencial compreendermos como ocorre está prática, além de problematizar as diferentes concepções de avaliação presentes nas trajetórias escolares.

\section{AVALIAÇÃO - DA ESCOLA ESPECIAL À ESCOLA REGULAR INCLUSIVA: "MEMÓRIAS" DE UM ALUNO COM DEFICIÊNCIA INTELECTUAL}

O tempo da escola é tão conflitivo porque foi constituído faz séculos e terminou-se cristalizando em calendários, níveis, séries, semestres e bimestres, rituais de transmissão, avaliação, reprovação e repetência. (ARROYO, 2004, p.192)

A Trajetória escolar de JC é marcada por experiências singulares, no período em que frequentou classe regular, classe especial, instituições especializadas até retornar a uma classe regular novamente em uma escola de Rede Estadual de Ensino em Belém/PA. A trajetória escolar de JC é marcada pelo seguinte "trânsito":

\section{TÍTULO: Quadro representativo da trajetória escolar de JC entre a escola regular e a} classe e instituição especializada

\begin{tabular}{|r|r|r|r|}
\hline PARADIGMA & INSTITUIÇÃO & ANO/SÉRIE/ET & PERÍODO DE \\
\hline
\end{tabular}




\begin{tabular}{|c|c|c|c|}
\hline & & APA & PERMANÊNCIA DE JC \\
\hline \multirow{3}{*}{ INTEGRATIVO } & Escola Regular & $1^{\mathrm{a}}$ série & 1987- 1989 \\
\hline & Classe Especial & $\begin{array}{c}\text { Período de } \\
\text { preparação para o retorno ao } \\
\text { ensino regular. }\end{array}$ & $1990-1998$ \\
\hline & Escola especial & $\begin{array}{l}\text { Aprendizagem de } \\
\text { ofícios. }\end{array}$ & 1999-2002 \\
\hline INCLUSIVO & Escola Regular & $\begin{array}{l}1^{\text {a }} \text { série ao } 3^{\circ} \text { ano } \\
\text { do Ensino médio cursado } \\
\text { em etapas. }\end{array}$ & 2003-2011 \\
\hline
\end{tabular}

FONTE: Elaborado pelas autoras com base na documentação e memória de JC.

A trajetória escolar de JC inicia-se, de fato, em 1985, período em que o Brasil ancora-se no modelo integrativo; perspectiva essa que é decisiva para a passagem do aluno da escola regular para a classe especial. No decorrer das entrevistas, foi possível identificar que o início da vida escolar de JC foi aos 5 anos de idade, em uma turma regular, já que o aluno até então, não possuía o diagnóstico de pessoa com deficiência intelectual. No ano seguinte cursou a alfabetização. Em 1987, aos 7 anos, ingressou na $1^{\text {a }}$ série, ficou nesta até 1989 (dos 7 aos 9 anos). Segundo consta em seus pareceres, no aspecto relacionado à escolarização:

[...]. Iniciou com 5 anos no pré-escolar-jardim. Com 6 anos fez alfabetização e com 7 anos foi para a $1^{a}$ série, onde está com tri-repetência. (Parecer sobre JC-preenchido em 1990, grifo nosso)

Quando JC ingressou na escola regular, na década de 1980 a ênfase na leitura e escrita direciona as memórias de JC, corroborando com a abordagem conteudista da qual afirmam Queiroz et al (2015). Esta se fez presente durante os anos iniciais da escolarização do aluno, principalmente quando atribui o fato de não ter adquirido a leitura ao seu insucesso nas avaliações da $1^{\mathrm{a}}$ série do ensino fundamental, conforme o relato abaixo.

[...] não sabia ler, todo mundo já sabia e eu nada. Todo mundo aprendia ..." (Relato de JC-sobre a escola na qual cursou a primeira série do ensino fundamental)

O trecho do relato acima evidencia que JC assume a responsabilidade pelo seu "não aprendizado". Na mesma medida em que reconhece o avanço dos demais, identifica em si mesmo a fragilidade, talvez, o obstáculo para aprender.

Cabe destacar, no entanto, que os processos avaliativos foram historicamente baseados na homogeneização dos alunos; desta forma, pouco contribuiu para que JC pudesse vivenciar alguma 
experiência de "sucesso" escolar, adverso a isso, agravou a descrença sobre sua capacidade de aprender. Este modelo de ensino não gerou as mesmas condições de aprendizagem para todos os alunos, evidente no caso de JC, que inicia uma história de retenções na $1^{\text {a }}$ série do ensino fundamental.

Ao longo de sua história a escola tem optado por avaliações homogêneas e descontextualizadas, uma vez que o dado é coletado de maneira acrítica e se encerra nele mesmo (LUCKESI, 1995); isto é, após a informação reproduzida na prova e/ou trabalho, o assunto é encerrado. Na concepção do autor a avaliação deve ir além do ato de classificar, pois um ensino baseado apenas no que já foi produzido, em detrimento às ações que poderiam ser realizadas pela escola, não favorecerá o processo de ensino e aprendizagem dos sujeitos com ou sem defíciência.

Na década de 1980, período em que JC ingressa na escola, normalmente crianças sem dificuldades eram aquelas que apresentavam avanços, realizavam as atividades. Já aquelas que não conseguiam, a escola cumpria seu papel: o de separar, classificar e induzir o olhar a enxergar somente o que o aluno não conseguia realizar. As diferenças eram neutralizadas e a ênfase voltavase para as dificuldades, fato este internalizado pelo próprio aluno:

[...] Aprendi a, e, $i, o, u$. Mas, não sabia ler, não aprendia ler $e$ nem copiar direito do quadro. (Relato de JC)

Outro aspecto interessante, que nos chama atenção neste trecho do depoimento de JC, é a menção sobre o raso conteúdo curricular que aprendeu. Quando indagado sobre o que aprendeu referente aos conteúdos curriculares, a ênfase voltava-se para as dificuldades com as notas, demonstrando que os impedimentos na primeira série do ensino fundamental, foram maiores do que seu aproveitamento.

[...] a professora passava ditado eu ficava sem fazer nada. Recortava e colava da revista. Quando era pequeno nunca passava de ano, minha nota era 0,0,1,2,3. (Relato de JC ao ser questionado sobre o que aprendeu durante o tempo que permaneceu na $1^{a}$ série)

O que se destacou no depoimento é que a sala de aula não foi o espaço por excelência utilizado no desenvolvimento das atividades curriculares. A escola, como instituição social, passou a auxiliar no processo de homogeneização da sociedade, através da transmissão cultural, constituindo-se como uma instituição baseada em princípios que visavam homogeneizar sua clientela, fracionar e hierarquizar saberes e pessoas. (LUNARDI, 2004) 
Tal apontamento ajuda a compreender esse modelo de cidadão que a escola vem ensinando ao longo dos séculos, constituído prioritariamente para a lógica do mercado, fornecendo o acesso a determinados conteúdos, e ao mesmo modelo avaliativo que todos os alunos devem dominar, sob o risco de serem considerados “inadequados” às normas e padrões comuns.

A organização escolar naquele contexto, já possuía "procedimentos" para o aluno que "destoava" dos padrões exigidos. Após dois ou três anos de reprovações seguidas, deveria ser enviado para a classe especial, como revela a pesquisa de Kassar (2006) ao retomar depoimentos de professores que atuavam em classes especiais ao final da década de 1980:

A gente conversava com o professor da $1^{\mathrm{a}}$ série: “- Se tiver aluno, assim, que não esteja acompanhando a turma...” e aí eles mandavam pra gente. Por exemplo, número de repetências, dois anos na $1^{\text {a }}$ série já era clientela de classe especial. (Professora Regina, 17 anos de magistério, relatando os encaminhamentos para classes especiais. Depoimento colhido em 1990) (KASSAR, 2006, p. 68)

A pesquisa remete à ausência de suporte às necessidades educacionais do aluno; ou seja, a forma mais imediata de lidar com o insucesso escolar e a repetência era seu encaminhamento a uma classe especial.

Após três anos de retenções consecutivas, o aluno foi submetido a um teste de QI, realizado por psicólogos da Secretaria Municipal de Educação de Belém/PA, cuja conclusão foi favorável ao ingresso de JC na Classe Especial. Na conclusão do teste de QI, o baixo desempenho de JC é atribuído a dois fatores: à dificuldade em algumas áreas do desenvolvimento e ao próprio aluno. No entanto, à escola não é atribuída nenhum tipo de responsabilidade, como se sua preocupação fosse apenas "identificar" se está havendo a apropriação do conteúdo, se eximindo da responsabilidade com este aluno.

Ao realizar o teste de QI, JC apresentou uma pontuação baixa, logo foi diagnosticado com a idade mental de uma criança de 7 anos, quando sua idade cronológica na ocasião era de 10 anos e 8 meses, fator que contribuiu para a baixa autoestima apresentada em trechos de sua trajetória.

Ao descobrir mais sobre a avaliação de JC na classe especial, ficou evidente que o aluno, ao invés de tentar compreender as atividades propostas, acabava demonstrando o posicionamento de quem não queria fazer, quando, na verdade, não sabia fazer. Conforme apresento no trecho citado: 
[...] Fazia prova às vezes, quando não entendia desistia de fazer, a professora deixava. O dever também, fazia quando era fácil. (Relato de JC ao ser questionado se realizava trabalhos ou provas na classe).

Percebem-se, a partir do relato de JC, dois aspectos importantes: 1) como a escola atribui certa irrelevância em sua avaliação, já que o aluno realizava conforme sua vontade; 2) havia pouca preocupação da escola com seus interesses e suas dificuldades durante a realização das provas e deveres.

Acredita-se que a avaliação pode proporcionar a emancipação do aluno com deficiência; o educando precisa ser capaz de dizer o que aprendeu, o que acha interessante estudar e como o conhecimento modifica sua vida. A função da avaliação não é medir se o aluno chegou a determinado ponto, mas se ele cresceu, e se está aos poucos vencendo suas limitações (AIMI E TAMBORIL, 2011). Adversa ao que prega as autoras é a situação vivida por JC durante o tempo que permaneceu na classe especial. $O$ aluno realizava as atividades quando acreditava ser interessante, ou quando acreditava ser possível realizar, ou seja, quando the parecia "fácil", contribuindo com a ideia de impossibilidade acentuada pela escola durante o período na educação especial.

O segundo fator, a falta de preocupação com suas dificuldades na realização das provas e deveres, acredito que tenha relação com a forma como se pensava que ele aprendia na época, ou seja, o que ele fosse "capaz" de aprender já se apresentava como satisfatório durante seu processo de ensino-aprendizagem. Desta forma, a escola proporcionava o acesso a conteúdos mínimos.

Outro ponto que merece destaque é que, conforme evidencia a pesquisa de Januzzi (2004), o intuito das classes especiais era viabilizar o retorno deste aluno a sala regular, a filosofia que permeou as classes especiais envolvia a tentativa de integrar as pessoas com deficiência em ambientes educacionais com o mínimo de restrição possível, pensando em possibilitar o posterior ingresso nos espaços comuns a todos. Desta forma, JC criava muitas expectativas em relação ao seu retorno à sala regular.

\section{[... ] fazia prova pra ver se já podia sair da classe. (Relato de JC)}

Até que no ano de 1996 essa expectativa é alcançada. Após seis anos na classe especial foi retirado para cursar a $2^{\mathrm{a}}$ série na sala regular. No entanto, segundo seu relatório não apresentou "bom rendimento", fato este que o fez retornar a classe especial por mais 2 (dois) anos, aí 
permanecendo até 1998. O período que JC permaneceu na classe especial pouco contribuiu para o acesso aos conteúdos curriculares, que é percebido claramente na seguinte memória:

[...] Aprendi a ler um pouquinho lá na classe, eu aprendi a contar e a escrever. Até hoje, não leio muito bem, acho que não aprendo a ler rápido. (Relato de JC sobre o que aprendeu na classe especial)

Esse período da escolarização de JC mostrou que é comum o aluno com deficiência sentir culpa por não aprender como os demais. O aluno internalizou a limitação referente à leitura. A postura que assume é a de recusa do saber, ao invés de afirmar não saber, como se o currículo da forma como se apresentava fosse inviável para ele.

A trajetória de JC continua quando ingressa em outro modelo integrativo no ano de 1998 (quando possuía 18 anos). É matriculado em uma instituição estadual especializada em alunos com deficiência intelectual, permanecendo até o fim do ano de 2002 (quando possuía 22 anos). O aluno foi encaminhado para a instituição especializada para alunos com deficiência intelectual, pois, no entendimento dos professores da classe, ele necessitava aprender ofícios. Além da profissionalização que ofertava oficinas de panificação, sapataria, jardinagem, entre outros, o aluno ainda teria acesso a atendimentos clínicos, como: fonoaudiologia, psicologia e assistência social. Portanto, nessas instituições o atendimento prioritário era o profissionalizante e o da área da saúde, em detrimento do educacional. Ou seja, JC foi submetido a uma série de atendimentos com pouca ou nenhuma relação com o currículo escolar, aspectos como o comportamento e sua tolerância ao participar das atividades da instituição ganhavam mais ênfase do que o aspecto educacional.

No parecer é possível destacar que as habilidades eram voltadas ao comportamento do aluno, como "acatar ordens", "bom comportamento", "tolerar carga horária”, ou seja, nesse caso, JC acabou não recebendo apoio para as questões educacionais. Essa forma de organização acentuou o distanciamento entre a instituição e a escola, e acabou estagnando ainda mais sua escolarização.

Mesmo com estas dificuldades evidenciadas na trajetória escolar do aluno, estas não se constituíram impedimentos para que permanecesse estudando e, posteriormente, acabasse migrando novamente para escola regular, naquele contexto, já inserida, pelo menos por obrigatoriedade legal, num outro modelo de escolarização, a inclusão.

Apesar das críticas destinadas a forma como o aluno é visto por essa escola, devo considerar o período no qual se deu esta trajetória. Esse dado é importante porque considerando que vivenciou o modelo integrativo por 12 anos consecutivos, sua trajetória foi permeada por uma escola que historicamente excluiu, ou que criou mecanismos de segregação pela necessidade de normalização 
deste sujeito. Para, além disso, é necessária a preocupação com a própria compreensão da escola sobre a deficiência e as formas de escolarizar e avaliar excludentes.

Diante de tal discussão, compreendo que a base conceitual da escola no período de 1990 a 2002 (período da classe e escola especial), referente à escolarização de JC traz características de uma educação com resquícios segregacionistas e tradicionais. Apesar da intenção de uma educação que promovesse o posterior ingresso na sala regular e outra que visava o ensino de ofícios, essas ações e formas de avaliar ainda apresentam marcas de segregacionismo que marcaram negativamente a relação de JC com a escola e da escola com JC.

O retorno de JC à escola regular se deu no ano de 2003, aos 23 anos, motivado pela diretora da escola especializada. Seu retorno constitui-se necessariamente no reinicio da escolarização desde o $1^{\circ}$ ano do ensino fundamental. Desta forma, o aluno seguiu com grande expectativa em relação ao espaço escolar, relembra como foi tecendo sua experiência na escola regular, demonstra todo o otimismo e expectativa de um adulto que "reinicia" sua escolarização, relembrando os auxílios recebidos, os professores que o inspiraram. No entanto, relembra também, as experiências escolares marcadas por certa falta de "investimento" em relação à sua aprendizagem, apresentadas pelo aluno, principalmente através do aspecto avaliativo.

JC relata muitas dificuldades na aprendizagem dos conteúdos curriculares, e nas avaliações; no entanto, a maioria dos alunos com ou sem deficiência apresentavam a mesma dificuldade, principalmente no segundo segmento do ensino fundamental e ensino médio. Entretanto, o estigma de inferioridade sentido pelo aluno, talvez o impedisse de aprender mais do que a própria dificuldade nos conteúdos curriculares, conforme o registro a seguir:

[...] Era matéria pesada, era raiz quadrada, baixar não sei o que, isso é muito pesado pra mim (Relato de JC)(grifo meu)

[...] As provas era difícil, tinha professor que passava prova de 32 marcar, o outro só de escrever, sempre tinha prova. Tinha trabalho também, mas pra passar valia a prova. (Relato de JC)

[...] Fazia a prova na doida mermo, passava ou não passava. Ela [colega de turma] dizia: -Tu vai passar JC? Eu dizia:- Não sei. (Relato de JC)

As provas foram consideradas uma das preocupações de JC, já que constituía o principal instrumento para atribuição de nota, seus relatos remetem sempre a muitas dificuldades e incertezas em relação aos aspectos avaliativos. 
[...] Fazia prova, quando olhava não sabia o que estava escrito, fazia bolinha e marcava qualquer coisa pra não entregar sem nada. (Relato de JC sobre a realização das avaliações)

O reflexo das memórias leva a certa imprecisão sobre o aspecto da avaliação de JC e da falta de diversidade de instrumentos avaliativos. A avaliação dos alunos com deficiência é citada como um dos principais fatores que inviabilizam a concretização da inclusão, como afirma Pletsch (2013), associada a outras dificuldades.

De maneira geral, a prática avaliativa ocorreu na trajetória do aluno, consoante ao desenvolvimento do medo da reprovação, não muito diferente do que ocorre com os alunos que não apresentam deficiência. O medo da reprovação revela uma avaliação que, por vezes, não é utilizada como instrumento capaz de compreender os avanços e os limites existentes no decorrer da caminhada dos alunos com ou sem deficiência.

Dito isso, a avaliação para JC deveria servir para apontar caminhos e explorar suas possibilidades de aprendizagem, sem rotular, nem transformar o ato em mais um contribuinte ao estigma sofrido por estudantes que não se enquadram no modelo de aluno cartesiano ideal (SENNA, 2007).

Curiosamente, o Ensino Médio realizado em 2010/2011 é marcado por relatos de superações. Ora dificuldades são apresentadas, ora ultrapassadas. Esta etapa de ensino acompanha novos desafios para JC. Mesmo com o aumento do grau de dificuldade do currículo e o acréscimo de disciplinas e carga horária, seus documentos evidenciam médias consideradas dentro da média, o mesmo que ocorre no ensino fundamental.

É importante reconhecer que as "médias altas" presentes no histórico do aluno, não significam um bom desempenho nos procedimentos avaliativos.

É preciso reconhecer que cada aluno aprende de uma forma, e com um ritmo próprio. Respeitar a individualidade de todas as pessoas significa dar oportunidades para todos aprenderem os mesmos conteúdos, fazendo as adequações necessárias do currículo. (HEREDERO, 2010, p. 198)

No entanto, acredito que a dificuldade sentida nos conteúdos escolares, é um fator que abrange a maioria dos alunos, apresentando ou não alguma deficiência. Apesar de sempre ressaltar dificuldades, os dados revelam e sua memória também, especialmente nos processos avaliativos que JC transitou pela escola regular apenas com uma reprovação no $\left(1^{\circ}\right.$ ano) e uma dependência na $6^{\text {a }}$ série. Consideradas “diferentes" e marcadas por estigmas e por imagens negativas e, apesar de 
acontecidas há muito tempo, deixaram marcas em JC que levaram da euforia do ingresso na escola, a frustração vivenciada com o decorrer dos anos na escola regular.

Falei pras meninas: - Não vou mais não, vou desistir, vou dá baixa lá, muito pesada essa matéria".

Elas diziam: Não desiste não JC, a gente te ajuda.

Falei:- Ta bom, vou ficar, vou terminar pela minha sobrinha! (Relato de JC quando questionado sobre a possibilidade de evadir)

A decisão de evadir da escola perpassa a trajetória do aluno, de forma mais forte, nos anos finais de sua escolarização na educação básica. Observa-se, nesse sentido, que os mecanismos da avaliação adotados produzem exclusão naquilo que poderia se constituir elemento de inclusão.

De um modo ou de outro, em 2011, JC conclui sua trajetória na Educação Básica.

\section{CONSIDERAÇÕES FINAIS:}

O desenvolvimento desta pesquisa foi permeado por um intenso diálogo, constituído de narrativas e da análise documental. Ambos se completaram na busca de pistas para entender o percurso constituído por diferentes experiências escolares vividas por JC, em especial por meio do processo avaliativo.

No contexto geral da trajetória de escolarização analisada, procuramos compreender como ocorreram os processos avaliativos deste estudante em diferentes paradigmas, ora integrativos,ora inclusivos, até a conclusão de sua escolarização básica.

Ouvir JC se constituiu um dos encantos da pesquisa, já que a opção por privilegiar sua escuta, possibilitou-nos um novo olhar sobre os processos de escolarização/avaliação e para a compreensão da inclusão de alunos com deficiência intelectual.

As memórias escolares mostram o quanto à organização da escola foi e continua sendo inadequada às necessidades dos alunos com deficiência intelectual, dificuldade esta relatada quando JC nos remete a sua $1^{\text {a }}$ série do ensino fundamental, e a retenção ocorrida durante 3(três) anos seguidos, o diagnóstico de sua deficiência aos 10(dez) anos de idade, e o consequente encaminhamento para um outro modelo de ensino diferente do qual conhecera durante 8(oito) anos consecutivos, incorporando em JC a perspectiva de impossibilidade.

Sobre as relações estabelecidas entre JC e a escola, o aluno descreve que seu processo na $1^{\mathrm{a}}$ série ocorreu da seguinte forma: o aluno reprovava, repetia, reprovava, repetia e entre essas reprovações e repetições de séries ficou à mercê de um sistema que o rotulou como incapaz, com 
problemas para aprender, tornando-o fracassado. A partir dessa incursão, depreende-se que as relações estabelecidas com a escola cumpriam uma "simulação do acompanhamento das atividades" criando a falsa impressão de que o aluno ao ouvir ou copiar do quadro estava aprendendo o conteúdo apresentado conforme os demais. Logo é direcionado a uma classe especial onde permanece muitos anos neste modelo integrativo; o fracasso, não deixa de ser uma produção, em meio a muitas perdas ocorridas em seu percurso.

Neste contexto, questionamos a pouca contribuição da escola no processo de ensinoaprendizagem e sua abordagem tradicional ao identificar as dificuldades do aluno e não intervir para seu desenvolvimento. Pelo contrário, apenas classificá-lo, visando recolocá-lo em outro modelo educacional, sem questionar a necessidade de mudança da escola.

$\mathrm{O}$ reingresso ao ensino regular representou um novo momento na trajetória de JC, momento permeado por dificuldades e inadequações evidentes quando esse sujeito vai avançando as séries/anos finais do Ensino Fundamental e do Ensino Médio. Nesse período de sua escolarização fica evidente as dificuldades em relação aos aspectos avaliativos, como sendo fatores que transpassaram sua trajetória na escola inclusiva.

A incursão pela trajetória de JC trouxe argumentos para construir a ideia de que o objetivo da escola vai além da contribuição no desenvolvimento de capacidades cognitivas, sobretudo deve (ou pelo menos deveria) contribuir para potencializar todas as capacidades do ser humano. Enquanto os aspectos cognitivos se constituírem o "único" benefício da escola, os alunos com deficiência intelectual estarão em desvantagens durante a escolarização.

A escolarização de JC, durante boa parte dos 26 (vinte e seis anos) que levou para concluir a escola básica, girou em torno de sua limitação ou incapacidade, já que as suas potencialidades e aptidões em raras ocasiões foram levadas em conta.

Por fim, no contexto geral da trajetória de escolarização observada, percebi que a educação básica não pode se reduzir a uma quantidade de anos/ conteúdos ou avaliações. Não se refere a níveis de ensino delimitados em uma faixa etária, sua abrangência deve incluir aspectos de um conhecimento escolar e formativo com sentido.

\section{REFERÊNCIAS:}

AMARAL, Tatiana Platzer do. Deficiência Mental Leve: processos de escolarização e subjetivação. São Paulo/USP.Doutorado em Psicologia,2004.

ARROYO, Miguel G. Imagens quebradas: trajetórias e tempos de alunos e mestres. 3. ed. Petrópolis: Vozes, 2004. 
BAPTISTA, Cláudio Roberto (org.). Inclusão e escolarização: múltiplas perspectivas. -2ed.-Porto Alegre: Mediação, 2015,192p.

BRASIL, Secretaria de Educação Especial. Política Nacional de Educação Especial na Perspectiva da Educação Inclusiva. Brasília, DF, jan. 2008a. [Documento elaborado pelo Grupo de Trabalho nomeado pela portaria n. 555/2007, prorrogada pela portaria n. 948/2007, entregue ao ministro da Educação em 7 de janeiro de 2008]. Disponível em:http:portal.mec.gov.br/arquivos/pdf/arquivos/pdf. Acesso em: jul 2018.

BUENO, J.G.S.; MENDES, G.M.L.; SANTOS, R.A. Deficiência e escolarização: novas perspectivas de análise. Araraquara, SP: Junqueira\&Marin; Brasília: CAPES, p.43-66, 2008.

CARVALHO, Rosita Edler. Educação Inclusiva com os Pingos nos “Is”. 2. ed. Porto Alegre: Mediação, 2004/2005.

CRUZ, Miguel E. M. da. Fundação Pestalozzi do Pará: A educação Especial no Processo de Integração Social. Belém: CEJUP,1988.

FARIA FILHO, Luciano M. Escolarização, culturas e práticas escolares no Brasil: elementos teórico-metodológicos de um programa de pesquisa. In: LOPES, Alice C.; MACEDO, Elizabeth (orgs.). Disciplinas e integração curricular: história e políticas. Rio de Janeiro: DP\&A,2002, p.13-36.

FERREIRA, J. R. 1992, “Notas sobre a Evolução dos Serviços de Educação Especial no Brasil”, Revista Brasileira de Educação Especial, num. 1, pp. 101-107.

FERREIRA, Júlio Romero. Educação especial, inclusão e política educacional: notas brasileiras. In: RODRIGUES, David (org.). Inclusão e educação: doze olhares sobre a educação inclusiva. São Paulo: Summus,2006.

HEREDERO, E. S. A escola inclusiva e estratégias para fazer frente a ela: as adaptações curriculares. Acta Scientiarum: Education, Maringá, v.32, n.2, p.193-208, 2010.

KASSAR, M. C. M. Quando eu entrei na escola... memórias de passagens escolares. Cadernos Cedes $\mathrm{n}^{\circ} 68$. jan/abril, 2006. pp. 60-73.

LUCKESI, C.C. Avaliação da aprendizagem na escola: reelaborando conceitos e recriando a prática, $2^{\mathrm{a}}$ edição. Salvador Ba: Malabares Comunicação e Eventos 2005.

LUNARDI, G. 2004. Diferenciação Curricular nas políticas curriculares em Portugal e no Brasil. In: IV Colóquio LusoBrasileiro de Questões Curriculares, 2004, Rio de Janeiro. Anais...

MARCHESI, A. e MARTIN, E. Da terminologia do distúrbio às necessidades educacionais especiais. In COLL, Cezar; PALACIOS, Jesus; MARCHESI, Álvaro (orgs). Desenvolvimento psicológico e educação: necessidades educativas especiais e aprendizado escolar. Porto Alegre: Artes Médicas, 1995, p.7 -23.

MAZZOTTA, Marcos José da Silveira. Educação escolar: comum ou especial? São Paulo: Pioneira, 1987.

PLETSCH, M. D. Formação docente em tempos de inclusão escolar: em foco as práticas do atendimento educacional especializado. Rio de Janeiro, 2013. (no prelo)

PLETSCH, M. D. Repensando a inclusão escolar: diretrizes políticas, práticas curriculares e deficiência intelectual. Editoras NAU \& EDUR, Rio de Janeiro, 2010.

QUEIROZ, D. R; OLIVEIRA, F. R. G.; FREITAS, M. N.; CUNHA, N. C,; CUNHA, T. N. B. Saberes docentes nas décadas de 70 e 80. Cadernos da FUCAMP, v. 14, n. 21, p. 15-29, 2015.

SENNA, LAG. O problema epistemológico da educação formal: a educação inclusiva. In: SENNA, LAG (org). Letramento: princípios e processos. Curitiba: Ibpex; 2007b. p. 149-169. 


\title{
AS MARCAS DA AVALIAÇÃO NO PROCESSO DE ESCOLARIZAÇÃO DE UM ALUNO COM DEFICIÊNCIA INTELECTUAL
}

\begin{abstract}
Resumo: $O$ objetivo deste artigo é problematizar os processos avaliativos vividos por um aluno com deficiência intelectual durante seu processo de escolarização. Assim se propõe a responder a questão: Como se constituiu o processo avaliativo de um aluno com DI, em diferentes paradigmas educativos, durante sua trajetória de escolarização na educação básica? Desenvolvemos a pesquisa numa abordagem qualitativa, tendo como coleta de dados a entrevista semiestruturada aplicada ao aluno, bem como seus pareceres escolares. Como resultado, identificamos que os processos avaliativos vivenciados nos diferentes modelos de escola, ainda que marcados por estratégias distintas, é um fator endógeno à escola que colabora para construção de uma relação marcada pela estigmatização do aluno com deficiência.
\end{abstract}

Palavras-chave: Avaliação. Deficiência Intelectual. Escolarização

\section{LAS MARCAS DE LA EVALUACIÓN EM EL PROCESO DE ESCOLARIZACIÓN DE UN ALUMNO DEFICIENCIA INTELECTUAL}

Resumen: El objetivo de este artículo es problematizar los procesos de evaluación venidos por alumno con discapacidad intelectual durante su proceso de escolarización. Asís se propone responder a la pregunta: $\dot{c}$ Cómo se constituran el processo de evaluación de un alumno com DI en diferentes paradigmas educativos durante su trayectoria de escolarización en la educación bäsica?Hemos surgido la investigación em un abordaje cualitativo, teniendo como recolección de datos estrecha aplicada al alumno, así como sus opiniones escolares. Como resecado identificamos que los procesos evaluadores vivenciados en los diferentes modelos de escuela, aunque marcados por estratégias distintas, es un factor endógeno la escuela que colabora para la construcción de una relación marcada por la estigmatización del alumno con discapacidad.

Palabras -clave: Evaluación. Deficiencia intelectual. Enseñanza

\section{THE MARKS OF EVALUATION IN THE SHOOLING PROCESS OF A STUDENT WITH INTELLECTUAL DEFICIENCY}

Resume: The objective of this article is to problematize the evaluation processes experienced by a student with intelectual deficiency during his schooling process. Thus it proposes to answer the question: How was the evaluation process of a student with DI in different educational paradigms during his schooling trajectory in basic education?We developed the research in a qualitative approach, having as data collection the semistructured interview applied to the student, as well as his school opinions. As a result, we identified that the evaluation processes experienced in the different school models, although marked by distinct strategies, is an endogenous school factor which collaborates to build a relationship marked by the stigmatization of the disabled student.

Keywords: Evaluation. Intellectual Disability. Schooling. 